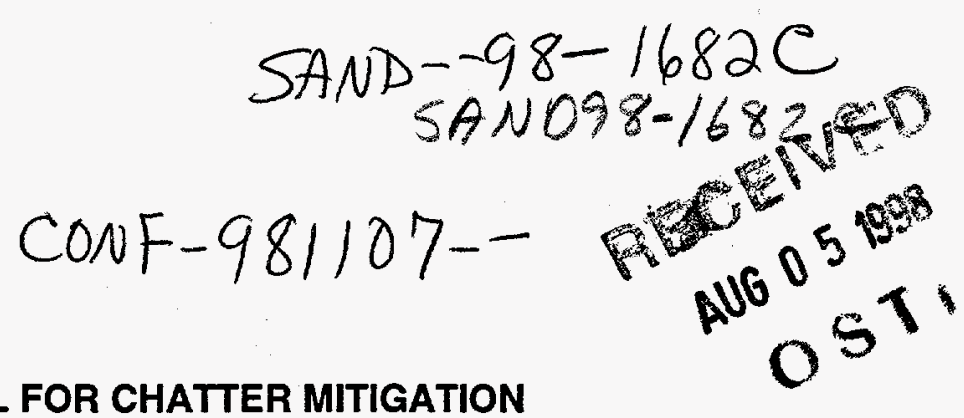

\title{
A BI-AXIAL ACTIVE BORING TOOL FOR CHATTER MITIGATION
}

\author{
James M. Redmond \\ Structural Dynamics and Vibration Control Department \\ Sandia National Laboratories \\ Albuquerque, NM 87185-0439 \\ Patrick S. Barney \\ Experimental Structural Dynamics Department \\ Sandia National Laboratories \\ Albuquerque, NM 87185-0557
}

\begin{abstract}
This paper summarizes results of metal cutting tests using an actively damped boring bar to suppress regenerative chatter. PZT stack actuators were integrated into a commercially available two-inch diameter boring bar to suppress bending vibrations. Since the modified tool requires no specialized mounting hardware, it can be readily mounted on a variety of machines. A cutting test using the prototype bar to remove metal from a hardened steel workpiece verifies that the actively damped tool yields significant vibration reduction and improved surface finish as compared to the open-loop case. In addition, the overall performance of the prototype bar is compared to that of an unmodified bar of pristine geometry, revealing that a significant enlargement of the stable machining envelope is obtained through application of feedback control.
\end{abstract}

\section{INTRODUCTION}

Recent advances in adaptive structures technology have renewed interest in the development of improved manufacturing processes featuring sensing, processing, and active vibration control. In particular, vibration suppression in metal cutting has received much attention because of its potential for enhancing part quality while reducing the time and cost of production. Nowhere is this more evident than in the boring process, which often requires the use of high length to diameter (L/D) cutting tools to satisfy geometric workpiece constraints. The use of such flexible tools is accompanied by regenerative chatter, a large amplitude tool vibration driven by workpiece surface undulations produced by previous tool passes (Merritt, 1965). Because it can cause premature tooling failure and workpiece damage, chatter is a matter of high consequence in the machining industry. This paper summarizes some test results obtained using an actively damped boring bar to suppress chatter.

For the boring process, active (Tewani et al., 1995) and passive (Kim and $\mathrm{Ha}, 1987$ ) vibration absorbers have been widely investigated, and some products offering single axis damping are now available on the commercial market. However, in light of recent research results which suggest that good performance can only be guaranteed through the implementation of bi-axial control, these devices are receiving limited attention. In response, some test results are now available using active tool clamps featuring bi-axial control, (Browning et al., 1997, Pratt and Nayfeh, 1998). The approaches adopted in these previous works, however, require specialized mounting hardware to interface the tool holder with a particular machine.

As an alternative to the previously mentioned vibration control schemes, the approach adopted in this project is to integrate piezoelectric stack actuators into the bar to enhance the damping with feedback control. Since no special tool holder is required, this technique provides the benefits of two axis control without the complications of additional machine interfacing hardware. Therefore, the prototype tool can be mounted on a variety of machines using conventional tool holders. During cutting, field induced axial strains in the stacks produce bending moments in the bar to counteract vibrations. A two-point preloaded mounting scheme allows positive and negative control moments while shielding the actuators from harmful tensile stresses. The efficacy of this approach for controlling bending vibrations of thick bar and plate like structures has been previously verified (Redmond and Barney, 1997).

The following section briefly describes the technique for integrating the stack actuators into the boring bar structure. Structurally integrated stack actuators are favored over surface mounted patches because they provide increased control authority without requiring excessive excitation levels. An overview of the prototype bar and the supporting data acquisition and control equipment is then related. A summary of cutting tests conducted on a hardened steel workpiece follows. These results include a comparison of the open and closed-loop performance of the prototype bar for a paricular set of cutting parameters. In addition, the closed loop performance over a range of cutting parameters is compared to the performance obtained using a pristine bar of identical make and model. Dramatic reductions in tool 


\section{DISCLAIMER}

This report was prepared as an account of work sponsored by an agency of the United States Government. Neither the United States Government nor any agency thereof, nor any of their employees, makes any warranty, express or implied, or assumes any legal liability or responsibility for the accuracy, completeness, or usefulness of any information, apparatus, product, or process disclosed, or represents that its use would not infringe privately owned rights. Reference herein to any specific commercial product, process, or service by trade name, trademark, manufacturer, or otherwise does not necessarily constitute or imply its endorsement, recommendation, or favoring by the United States Government or any agency thereof. The views and opinions of authors expressed herein do not necessarily state or reflect those of the United States Government or any agency thereof. 


\section{DISCLAIMER}

Portions of this document may be illegible in electronic image products. Images are produced from the best available original document. 


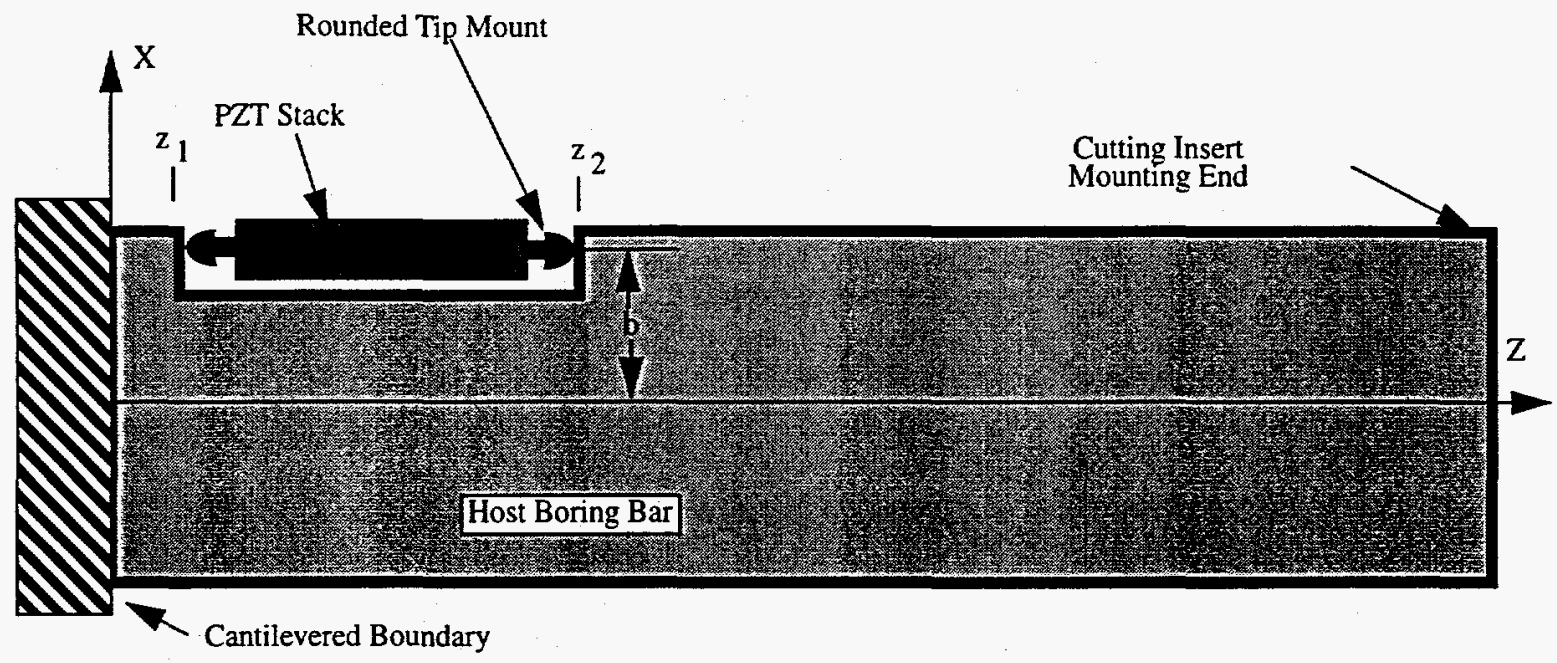

Figure 1. - Conceptual model of a boring bar with a structurally integrated PZT stack actuator located at the bar root.

vibrations and superior surface finishes are obtained through the implementation of active control.

\section{ACTUATOR INTEGRATION}

Controlling bending vibrations in thick bars and plates requires greater control authority than is available from conventional surface mounted actuators such as PZT patches. Instead, we propose to actively damp the boring bar by integrating PZT stack actuators into the boring bar structure. Mounted in material cutouts offset from the neutral axis, the actuators induce bending moments in the bar through their extensional deformation. While the coupling mechanism is only summarized here, a more thorough description can be found in previous publications (Redmond and Barney, 1997).

A conceptual representation of a bar with an actuator mounted in a cutout on the surface is shown in Fig 1 . The actuator is offset from the bar center line by a distance $b$, making contact only at the end points denoted $z_{1}$ and $z_{2}$ as measured from the bar root. The rounded tip, preloaded mounting scheme enables the production of a bending moment in the bar through field induced axial strain in the actuator. Furthermore, the two point contact shields the ceramic stack from any harmful tensile stress.

The modal controllability afforded by strain based actuation can be maximized by placing the actuators in locations of peak modal strain energy. For a cantilevered boring bar, this is typically near the bar root. Thus, as compared to active and passive tuned mass dampers, this approach has the added advantage of removing the actuators from the caustic environment of the cutting zone. However, modifications to the boring bar structure near the cantilevered end can have a detrimental effect on the bar's inherent stiffness. Therefore, performance enhancements resulting from active control can be quantified only by comparison to an unmodified bar.

With the optimal axial location of the actuators established, we briefly tum our attention to the task of determining the number and circumferential locations of the actuators needed to guarantee adequate performance. The development of regenerative chatter requires significant fluctuations in the chip thickness which can only result from tool tip displacements normal to the workpiece surface. Thus, since the boring bar is nearly axisymmetric, it is logical to assume that controlling vibrations along this axis alone would be sufficient to suppress chatter. However, nominal variations in the tool mounting procedures can alter the boundary conditions of the bar, leading to significant changes in the orientation of the bar's principal axes. The resulting coupling of the tangential and normal vibrations can then become problematic, since the tangential component of the cutting force is much larger than the radial component. The impact of variations in the bar's dynamics resulting from inconsistent mounting can be minimized by mounting as few as two actuators orthogonal to each other (Redmond et al., 1997). For the prototype bar, two actuators are mounted along the normal and tangential directions relative to the workpiece surface.

\section{EXPERIMENTAL SET-UP}

Cutting tests were conducted on a Binns and Barry horizontal lathe located at Sandia National Laboratories. The prototype boring tool, shown during a cut in Fig. 2, consisted of a two-inch diameter steel shank Valenite bar (model S32-MCLNL6) fitted with a titanium nitride coated Valenite cutting insert (model CNMP643 SV4). All cutting tests

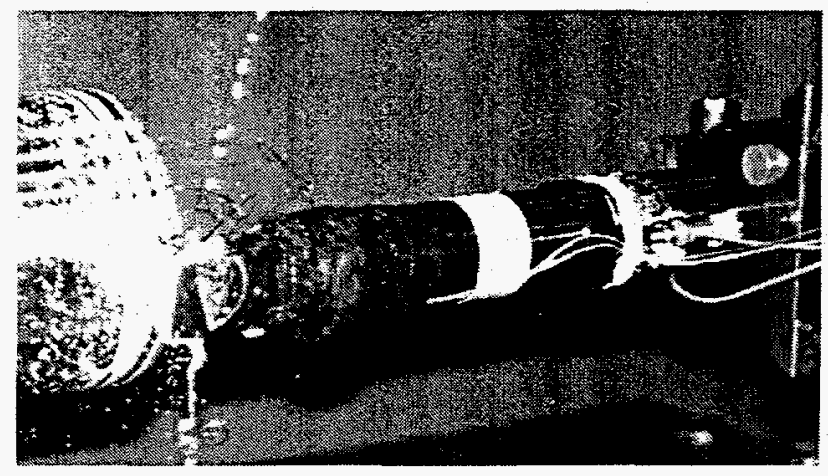

Figure 2. - Prototype Valenite boring bar with LD of 6 and actuators mounted near cantilevered end. 


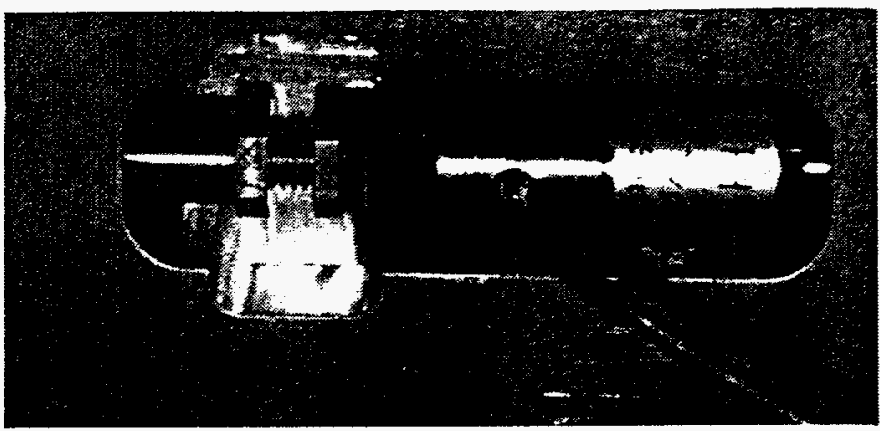

Figure 3. - Physik Instrumente actuator with rounded tip inserts preloaded into pocket with concave ends.

were performed with a bar L/D of 6 on a rigid 4340 steel workpiece that had been heat treated to a hardness of 42 Rockwell ' $C$ ' scale.

The bar was modified to incorporate Physik Instrumente PZT stack actuators (model 840.1) near the bar root as shown in Fig. 3. Two actuators were integrated into the bar structure, one each on the lower and aft portions of the bar to suppress bending vibrations tangential and normal to the workpiece surface, respectively. The actuators were mounted using mechanical pre-load, with the rounded actuator tips inserted into the concave pocket ends. A 20 volt bias was added to enable $+/$ - control inputs. Tip mounted Endevco accelerometers (model 22) provided the input to the two independent rate feedback control algorithms running on the dSpace controller. Performance was monitored using a Hewlett Packard 3565s system operating at 4096 samples per second.

Comparisons of the normal and tangential frequency response functions are given in Figs. 4 and 5, respectively. A double pole is

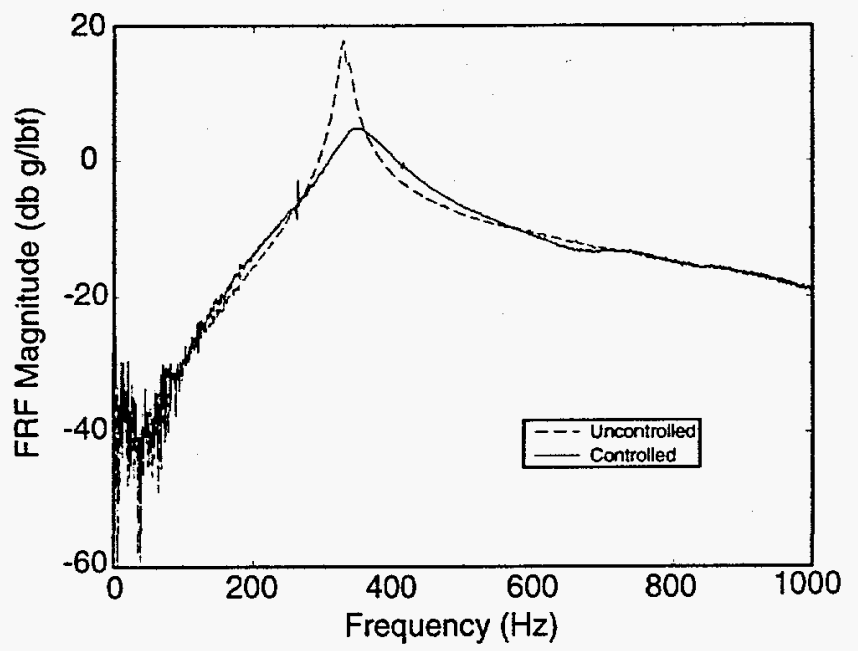

Figure 4. - Driving point FRF magnitudes measured tangential to the workpiece at the cutting tip with $L D=6$. evident in the vicinity of $330 \mathrm{~Hz}$, indicating the presence of the first bending mode in each of the normal and tangential directions. A 10-15 $\mathrm{db}$ reduction in the resonant peaks results from the application of the Active Vibration Control (AVC). The estimated first mode damping ratio in the tangential direction moved from $2.1 \%$ to $9.0 \%$ critical while an increase from $1.5 \%$ to $4.5 \%$ was realized in the normal direction.

\section{CUTTING TESTS}

In this section, a cutting demonstration is first summarized to illustrate the difference in bar vibration between the control-on and control-off cases. Although this example provides insight into how the AVC influences behavior, it does not adequately reflect the full potential of the AVC since there exists a fine line between stable and unstable cutting conditions. Furthermore, chatter prevention with AVC can often be effective for cases in which chatter elimination is not possible, since the amplitude of established chatter may exceed the stroke capacity of the actuators. In practice, the chatter prevention envelope under AVC can be much larger than the chatter elimination envelope. Thus, a survey of the stable machining envelope with AVC continuously activated is also presented. Results are compared to an unmodified bar to illustrate the performance enhancement enabled through AVC.

\section{Cutting Demonstration}

With the cut depth set at 0.015 inches and the AVC off, the cutting speed and feed rate were adjusted until a heavy chatter was sustained at $160 \mathrm{rpm}$ and 0.006 inches/rev. Acceleration measurements were recorded for 10 seconds prior to activating the AVC, after which 10 more seconds of data were recorded. Power spectra for these conditions

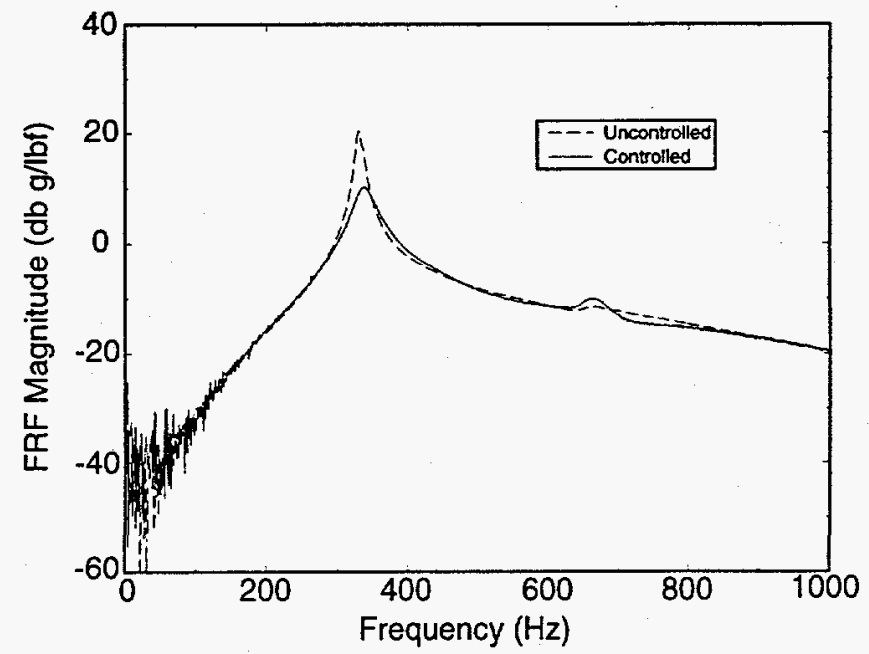

Figure 5. - Driving point FRF magnitudes measured normal to the workpiece at the cutting tip with $L D=6$. 


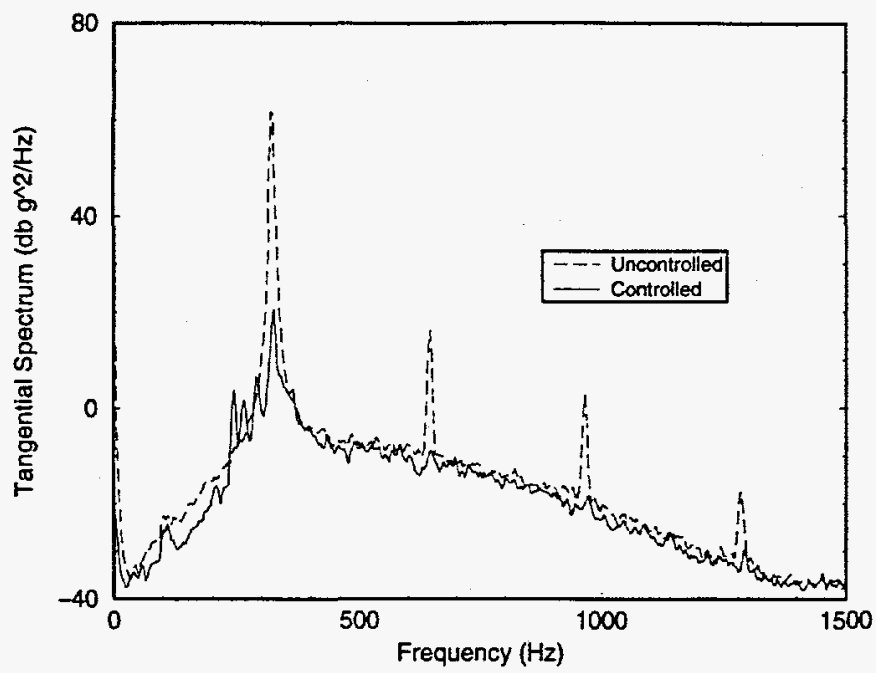

Figure 6. - Acceleration spectrum for 15 mil depth of cut measured tangential to the workpiece at the cutting tip.

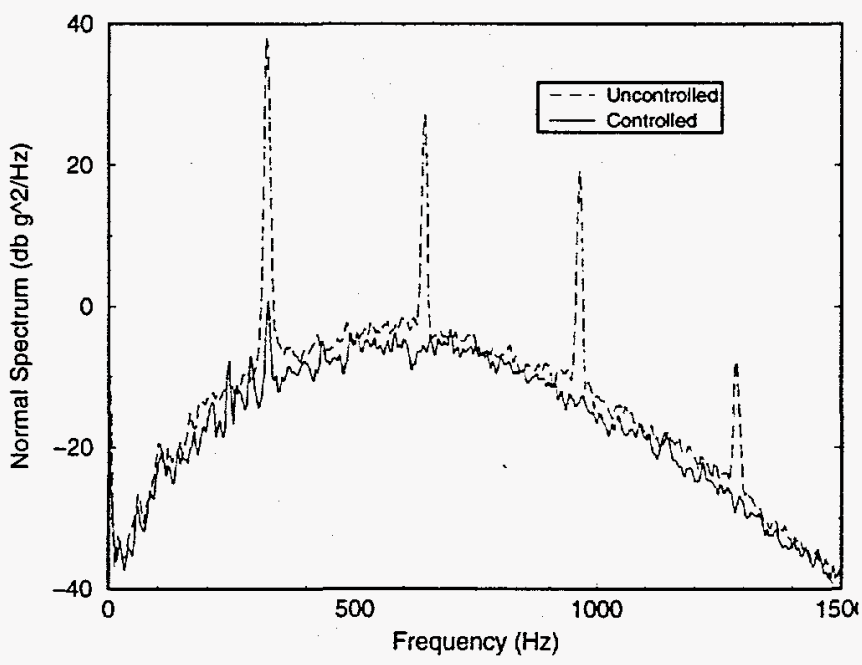

Figure 7. - Acceleration spectrum for 15 mil depth of cut measured normal to the workpiece at the cutting tip

are shown in Figs. 6 and 7. While the existence of the strong resonant peak and several harmonics for the uncontrolled case provide strong evidence of chatter, the absence of harmonic peaks with AVC indicate that the chatter was completely eliminated. The vibrational energy at the resonant peak for this case was reduced by $40 \mathrm{db}$. Several cycles of the corresponding tool tip displacement portraits estimated from a broad band frequency domain integration of the acceleration signals are given in Fig. 8. A dramatic reduction in tip vibration amplitude resulted from activation of the AVC, leading to an improvement of the workpiece surface finish $\left(R_{\mathrm{a}}\right)$ from 120 microinches to 60 microinches.

\section{Performance Assessment}

In the previous section, a sample cut was presented to demonstrate the effectiveness of the actively damped boring bar in eliminating

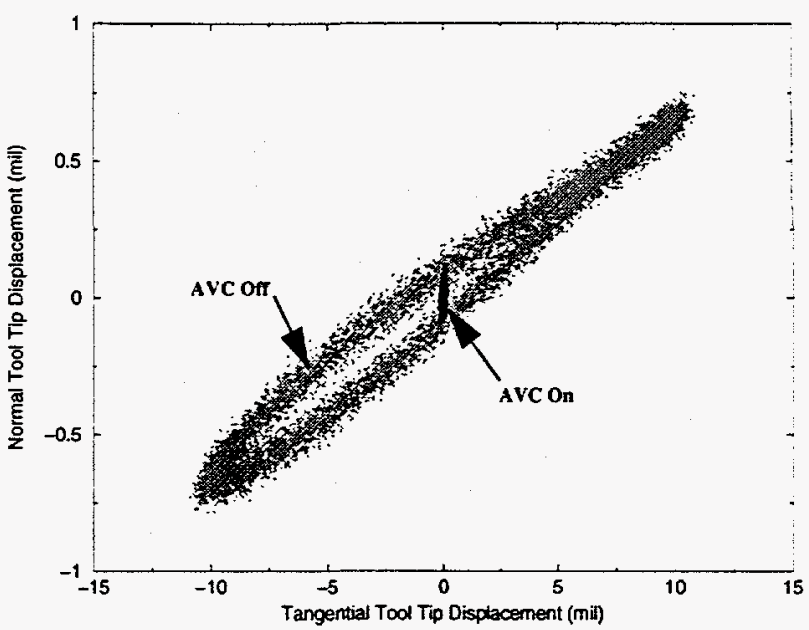

Figure 8. - Tool tip displacement portraits for open and closed-loop: 0.015 inch depth of cut, 0.006 inches per revolution feed rate, and workpiece speed of $160 \mathrm{rpm}$.

chatter. While a dramatic reduction in tool tip vibration was achieved for the chosen cutting parameters, assessment of the performance enhancements enabled through application of AVC requires closer scrutiny of the bar's behavior over a range of operating parameters. Furthermore, since incorporating the actuators into the boring bar required significant structural changes resulting in reduced static stiffness, an objective assessment requires comparison of the actively damped bar to an unmodified bar of identical make and model.

Toward that end, a test matrix was contrived to explore vibration amplitude as a function of speed and feed for both the actively controlled bar and a pristine bar. With the depth of cut fixed at 0.015 inches, the workpiece speed was varied from 75 to $180 \mathrm{rpm}$ and the feed rate was swept from 0.0015 to 0.0195 inches per revolution. At each point on the test matrix, ten seconds of normal and tangential tool tip accelerations were recorded after a steady state vibration level was achieved.

Figures 9-12 contain approximate rms tool-tip displacements for the test matrix. Displacements were again estimated from frequency domain integration of the acceleration data. For the unmodified bar shown in Figs. 9 and 10, chatter vibrations dominated the test matrix with the normal and tangential vibration amplitudes on the order of 0.001 and 0.010 inches, respectively. Although a small region of chatter free machining was encountered at the highest speeds and feed rates, these conditions were characterized by poor surface finishes. In contrast to the unmodified bar, the prototype bar with AVC yielded greatly reduced vibration levels over most of the parameter space considered as shown in Figs. 11 and 12. Only the lowest speeds with the highest feed rates produced appreciable vibration levels. Thus, for the conditions considered, the prototype bar drastically outperformed the unmodified bar and enabled the production of workpieces with acceptable surface finishes.

\section{CONCLUDING REMARKS}

A technique for actively suppressing regenerative chatter vibration in boring has been described. Piezoelectric stack actuators were integrated into the body of a commercially available boring bar to provide vibration control both normal and tangential to the workpiece 


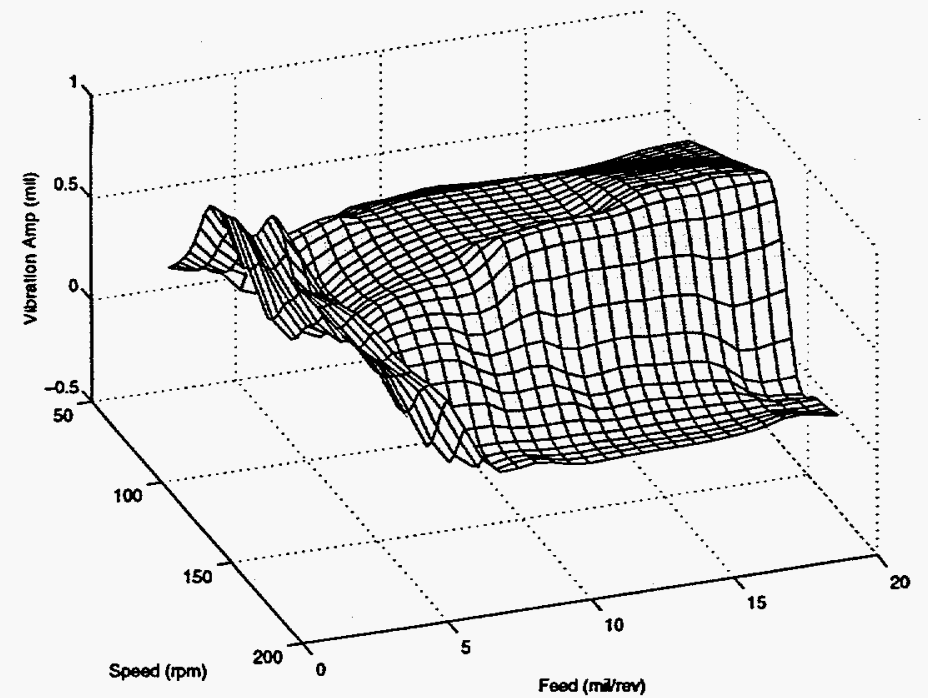

Figure 9. - Estimated tool tip vibration amplitude measured normal to the workpiece surface using an unmodified bar.

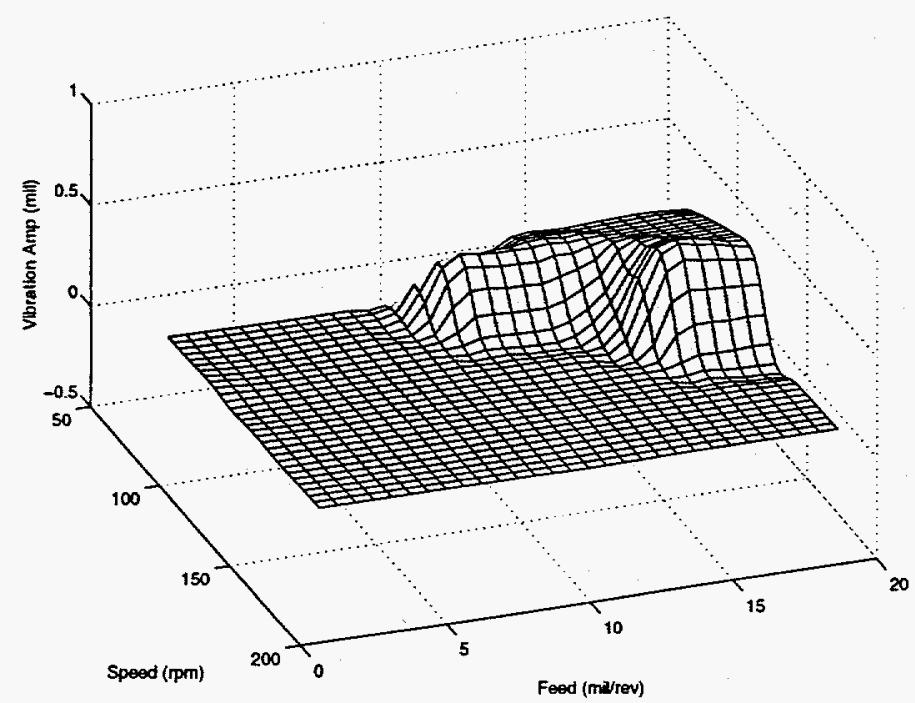

Figure 11. - Estimated tool tip vibration amplitude measured normal to the workpiece surface using the prototype bar.

surface. Unlike previous approaches featuring active tool holders, the structurally integrated actuators enable bi-axial control while utilizing conventional tool mounting hardware. Axial strain induced in the actuators through application of closed-loop control produces bending moments in the boring bar to counter cutting induced vibrations. The efficacy of this control approach was demonstrated in a series of cutting tests performed on a hardened steel workpiece. For the case of a bar with L/D of 6 , rate feedback control yielded dramatic reductions in tool vibrations for moderate metal removal rates as compared to an unmodified bar.

\section{ACKNOWLEDGEMENT}

This work was conducted at Sandia National Laboratories. Sandia National Laboratories is a multiprogram laboratory operated by Sandia

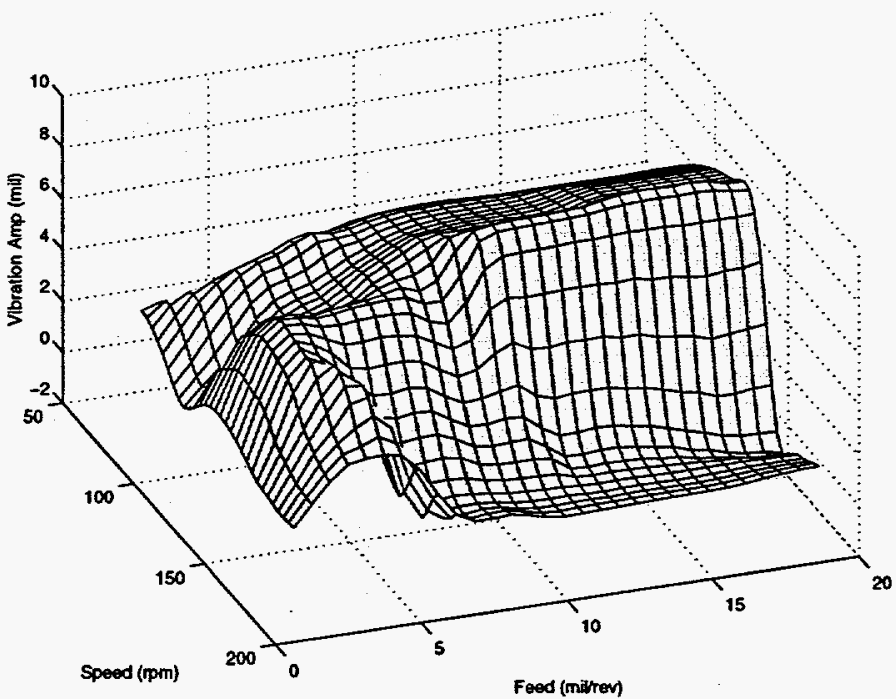

Figure 10. - Estimated tool tip vibration amplitude measured tangential to the workpiece surface using an unmodified bar.

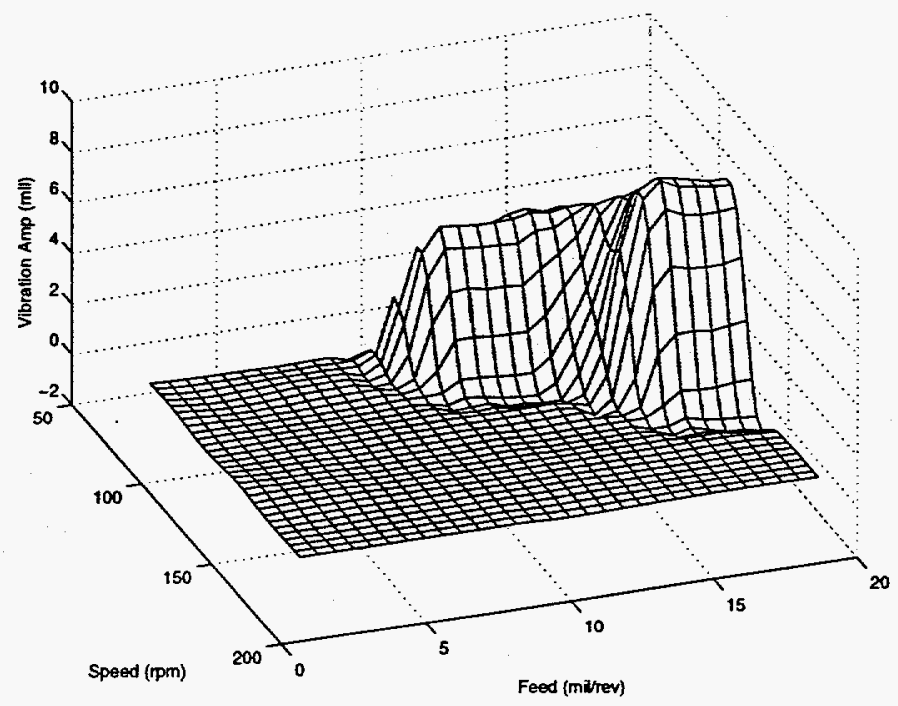

Figure 12. - Estimated tool tip vibration amplitude measured tangential to the workpiece surface using the prototype bar.

Corporation, a Lockheed Martin Company, for the United States Department of Energy under Contract DE-ACO4-94AL85000. The authors gratefully acknowledge the assistance of Terry Litts at SNL and David Smith at the University of Florida Machine Tool Research Center.

\section{REFERENCES}

Merritt, H.E., 1965, "Theory of Self-Excited Machine-Tool Chatter," Journal. of Engineering for Industry, November, pp. 447-453.

Tewani, S., Rouch, K., and Walcott, B., 1994, "A Study of Cutting Process Stability of a Boring Bar with Active Dynamic Absorber," International Journal of Machine Tools and Manufacturing, Vol. 35, No. 1, pp. 91-108. 
Kim, K.J. and Ha, J.Y., 1987, "Suppression of Machine Tool Chatter Using a Viscoelastic Dynamic Damper," Joumal of Engineering for Industry, Vol. 109, February, pp. 58-65.

Browning, D., Golioto, I., and Thompson, N., 1997, "Active Chatter Control System for Long Overhang Boring Bars," Proceedings of Industrial and Commercial Applications of Smart Structures Technologies, J.M. Sater, ed., SPIE-The International Society for Optical Engineering, Bellingham, WA, Vol. 3044, pp. 270-380.

Pratt, J., and Nayfeh, A., 1998, Proceedings of SPIE, SPIE-The International Society for Optical Engineering, Bellingham, WA, Vol. 3329.
Redmond, J., and Barney, P., 1997, "Vibration Control of Stiff Beams and Plates Using Structurally Integrated PZT Stack Actuators," Journal of Intelligent Material Systems and Structures, Vol. 8, No. 6, pp. 525-535.

Redmond, J., Barney, P., and Smith, D., 1997, "Development of an Active Boring Bar for Increased Chatter Immunity," Proceedings of Industrial and Commercial Applications of Smart Structures Technologies, J.M. Sater, ed., SPIE-The International Society for Optical Engineering, Bellingham, WA, Vol. 3044, pp. 295-306. 